\title{
Phenolic compounds with antioxidant capacity of the native Andean potato (Solanum tuberosum L.) Huagalina variety in La Libertad- Peru
}

\author{
Carmen Rojas-Padilla*; Víctor Vásquez-Villalobos
}

Escuela de Postgrado, Universidad Nacional de Trujillo, Av. Juan Pablo II s/n. Ciudad Universitaria, Trujillo, Perú.

Received March 15, 2016. Accepted June 18, 2016.

\begin{abstract}
Potato is grown and consumed throughout the world for their particular calorific nutritional value and vitamin C, but it also contains phytochemicals (secondary metabolites) that have been studied and found to have positive effects in preventing degenerative diseases in human health, such as hypertensive activity, and also atherosclerosis, type 2 diabetes, liver fibrosis, Alzheimer's disease, macular degeneration and cancer. We aimed to identify and quantify phenolic compounds in potatoes grown on El Zuro (EZ) and Huayatan Alto (HA) in Santiago de Chuco, La Libertad, Peru. The field trials were carried out in EZ (altitude 3750 m.a.s.l.) and HA (altitude 3150 m.a.s.l.) employing organic and inorganic fertilization respectively. Extraction from the peel and flesh was obtained separately, with the following solution: $50 \%$ methanol, 50\% deionized water and $0.5 \%$ acetic acid. The sample was injected into the system UPLC - MS / MS, using ESI ionization (Electrospray Ionization) and fifteen external reference standards. Thirteen metabolites were detected in the flesh and potato peel. The highest content of secondary metabolites (mg/100 g DW) were: Chlorogenic acid (476.82 \pm 63.58$)$, neochlorogenic acid $(87.90 \pm 19.42)$ caffeic acid (77.53 \pm 14.49$)$ and vanillin $(11.52 \pm 1.38)$. The PCA (Principal Components Analysis) scores show that the highest concentration of metabolites was found in the peel of both cultivars. We concluded that the native potato Huagalina contains the genes expressed in different biosynthetic pathways of the metabolites found in this study.
\end{abstract}

Key words: native potato, phytochemicals, cancer, diabetes, chlorogenic acid.

\section{Introduction}

Solanum tuberosum L. is one of the most important crops, which originated in the Peruvian Andes and is widely consumed worldwide (Bordoloi et al., 2012). According to FAO, world production of potatoes in 2012 was led by China $(85.86 \mathrm{E}+06 \mathrm{t})$ and India $(45 \mathrm{E}+06 \mathrm{t})$, Peru is in 18th place with $4.47 \mathrm{E}+06 \mathrm{t}$ (INEI, 2014). La Libertad (in the north of Peru) with $4.08 \mathrm{E}+05 \mathrm{t}$ of potato crop yield now ranks fourth in the national production (INEI, 2014); it has a diversity of natural conditions giving the region an important biological wealth which generates comparative advantages in the highlands over $3000 \mathrm{~m}$ above sea level where the native Huagalina potato, also called "Amarilla del Norte", is grown. Potato is

\footnotetext{
* Corresponding author

E-mail: crojasp@unitru.edu.pe (C. Rojas-Padilla).
}

the only major food crop that is a tuber, and is a food recognized as a good source of protein, carbohydrates, vitamin $\mathrm{C}$, vitamin B6 and vitamin B3 and certain minerals such as potassium, phosphorus and magnesium (André et al., 2009). It also contains phytonutrients or bioactive compounds which are the largest groups of secondary metabolites that occur as a response to the environment due to their high adaptability to grow in very diverse environments (Hawkes, 1990). Because of their beneficial effects on health (Navarre, 2009; Monro and Mishra, 2009) they are as important as phenolics, flavonoids, folate, anthocyanins, poly-amines and carotenoids (Ezequiel et al., 2013), which are considered as antioxidants, protecting against reactive oxygen species (ROS) DOI: 10.17268/sci.agropecu.2016.03.22 
when consumed through diet (Virgili and Scacini, 2003; Kris-Etherton et al., 2004). The bioavailability of these metabolites in potatoes seems to have benefits for human health, in anti-hypertensive activity, prevention of atherosclerosis, type 2 diabetes, Alzheimer's disease, cancer (Zhao and Moghadasian, 2010); there is also evidence of their inhibitory effect against HIV (Tamura et al., 2006), cataracts and macular degeneration (Chuah et al., 2008) and of antimicrobial properties (Muthuswamy and Ruspasinghe, 2007). As a therapeutic alternative, potatoes are also used empirically by the population for problems of the gastric mucosa, which shows that fresh potatoes and tocosh (an andean preservation technique) have an antioxidant defense and cytoprotective effect on the gastric mucosa (Sandoval-Vegas et al., 2010; Sandoval et al., 2015). There are many studies that have been conducted to determine antioxidant capacity and total phenolic compounds following in vitro protocols; the results are inconsistent for the validation of the conclusions; the main disadvantage of these assays is that they only give an estimation of antioxidant capacity and total phenolic content (Sharma and Bhat, 2009; Ignat et al., 2011).

Dixon et al. (2006) argue that biological systems are extremely complex, and that phytonutrients of vegetables produced in response to the environment are secondary metabolites, which reveal processes of gene expression, action of gene products, and resulting metabolic networks that contribute to the remarkable diversity inherent in living systems. In this sense, metabolomics emerges as a relatively new approach to improve our understanding of these networks and help determine the biochemical composition of plants and other biological organisms, thus, the aim of this research was to identify and quantify fifteen phenolic compounds in the peel and flesh of the native Huagalina potato with UPLC-MS/MS.

\section{Materials and methods}

\subsection{Chemical materials}

HPLC grade standards were obtained from Sigma-Aldrich (USA): 3,5-dihydroxybenzoic acid, neochlorogenic acid, chlorogenic acid, 4-hydroxybenzoic acid, caffeic acid, syringic acid, vanillin, $p$-coumaric acid, ferulic acid, sinapic acid, 4-hydroxy3-methoxy-cinnamaldehyde, coumarin, daidzein, genistein, 7-hydroxyflavone.

\subsection{Plant materials}

Field trials were carried out in Santiago de Chuco - La Libertad at two experimental sites: El Zuro (EZ) and Huayatan Alto (HA).

$>$ El Zuro (3 750 m.a.s.1.), soil with sandy loam texture, good drainage, moderate and deep slope, acid with a $\mathrm{pH}$ of 5.3, electrical conductivity: $0.3 \mathrm{dS} / \mathrm{m}$ (no salt), organic matter: $6.4 \%$ (very high), phosphorus $17 \mathrm{ppm}$ (high) and potassium 477 ppm (very high), annual average temperature $9{ }^{\circ} \mathrm{C}$ (dry, cold climate) and organic manuring (Guano de Islas 2 t/ha) under drought conditions.

> Huayatan Alto (3 450 m.a.s.1.), loamy soil and good drainage, with sloping slightly pronounced and moderately deep, acid with a $\mathrm{pH} 5.0$, electrical conductivity $1.5 \mathrm{dS} / \mathrm{m}$ (no salt), organic matter: $5.2 \%$ (high), phosphorus 14 ppm (average) and potassium $80 \mathrm{ppm}$ (low), the average annual temperature of $10{ }^{\circ} \mathrm{C}$ (temperate climate with presence of drizzles) and inorganic fertilization (180-200-160 kg of NPK/ha, under drought conditions.

Samples of harvested potatoes from EZ and HA were washed with tap water and allowed to dry. They were then manually cut into slices of $5 \mathrm{~mm}$ thickness, freeze dried and packaged with liquid nitrogen in sealed jars. They were transported by air to the Núcleo de Biomoleculas (NuBioMol) of the Federal University of Viçosa (Minas Gerais, Brazil). 


\subsection{Extraction}

The freeze-dried slices were carefully skinned with a scalpel to separate the peel from the flesh, and ground separately to obtain a fine powder. The following extraction solution (ES) was prepared: $50 \%$ methanol (HPLC grade - Sigma Aldrich), $50 \%$ deionized water and $0.5 \%$ acetic acid (Fluka Analytical HPLCgrade). Phenolic compounds were extracted from the peel and flesh separately, and used the ES described by Narváez-Cuenca et al., (2012). Each 0.02 g of peel powder and $0.02 \mathrm{~g}$ of flesh power were extracted separately with $500 \mu \mathrm{L}$ of the ES. The samples were mixed in vortex (VWR Analog Vortex Mixer, USA) 4 times for 10 seconds, sonicated (Branson Ultrasonic bath 3800 , USA) for $10 \mathrm{~min}$ at $4{ }^{\circ} \mathrm{C}$ and kept in ice (30 minutes). After centrifugation (Eppendorf 5424, Germany) $15000 \mathrm{~g}$ for 10 minutes at $4{ }^{\circ} \mathrm{C}, 350 \mu \mathrm{L}$ of the supernatant was removed and put in a new tube. The process was repeated two additional times with the resultant pellet and the supernatants were pooled. A final centrifugation (Eppendorf 5424, Germany) $20000 \mathrm{~g}$ for $10 \mathrm{~min}$ at $4{ }^{\circ} \mathrm{C}$ was performed to remove any remaining tissue suspension, and stored at $-80{ }^{\circ} \mathrm{C}$ until further analysis. The pellets were discarded.

\subsection{UPLC-MS/MS analysis}

The sample was automatically injected (5 $\mu \mathrm{l}$ ) in the system using UPLC (Agilent 1200 Infinity Series, USA) coupled to a Mass Spectrometry type triple Quadrupole (QqQ), (model 6430 Agilent Technologies, USA). Chromatographic separation was carried out on a column Zorbax Eclipse Plus C18 (1.8 $\mu \mathrm{m}, 2.1$ x $50 \mathrm{~mm})$ (Agilent, USA) in series with a guard column Zorbax SB-C18, $1.8 \mu \mathrm{m}$ (Agilent, USA). The solvent used was: (A) acetic acid $0.02 \%$ in water and (B) acetic acid $0.02 \%$ in acetonitrile (LC-MS grade, Fluka Analytical). The solvent flow rate was 0.3 $\mathrm{ml} / \mathrm{min}$ in a column temperature of $30{ }^{\circ} \mathrm{C}$. A linear gradient with the following solvent proportions of solvent B was used: gradient from 0 to 11 minutes, 5 to $60 \%$ of B; 11 to $13 \min 60$ to $95 \% \mathrm{~B} ; 13$ to 17 minutes $95 \%$ of $\mathrm{B} ; 17$ to $19 \mathrm{~min}$ and 95 to $5 \% \mathrm{~B} ; 19$ to 20 minutes, $5 \% \mathrm{~B}$. The ionization method used in the mass spectrometry was an ESI (Electrospray Ionization) following these conditions: gas temperature of $300{ }^{\circ} \mathrm{C}$, nitrogen flow rate of $10 \mathrm{~L} / \mathrm{min}$, nebulizer pressure of $35 \mathrm{psi}$ and capillary voltage of $4000 \mathrm{~V}$. The equipment was operated on mode MRM (Multiple Reaction Monitoring).

The mass of the established precursor ion/fragment $(\mathrm{m} / \mathrm{z})$ was monitored using fragmentation tests for each molecule:

3,5 dihydroxybenzoic acid (155.02/137.01), chlorogenic acid (355.00/163.00), 4hydroxybenzoic acid (139.12/121.00), 4hydroxy-3-methoxycinnamaldehyde (179.10/147.04), coumarin (147.06/91.00), daidzein (255.00/199.00), genistein (271.00/243.00), 7-hydroxyflavone (239.07/137.00), neochlorogenic acid (353.10/179.00), caffeic acid (179.00/135.00), syringic acid (197.00/121.200), vanillin (151.00/92.00), $p$-coumaric acid (163.04/119.00), ferulic acid (193.00/134.00), sinapic acid (223.00/164.10).

The first eight were scanned in positive mode and the last ones in negative mode. A calibration curve (from $0.1 \mathrm{ng}$ to $100 \mu \mathrm{g}$ ) using the respective standards of each metabolite was generated to determine the absolute quantification. The generated data were analyzed using "MassHunter Workstation" VB 06.00 software to obtain the peak areas for each phenolic metabolite and the results were expressed in $\mathrm{mg} / 100 \mathrm{~g}$ of dry tissue.

\subsection{Statistical analysis}

The Principal Components Analysis (PCA) was performed using XLSTAT 2015 Software (Digital license).

\section{Results and discussion}

Phenolic compounds found in the native Huagalina potato grown in EZ and HA are presented in Figure 1, and those with higher concentration (expressed in $\mathrm{mg} / 100$ g DW) are: Chlorogenic acid (476.82 \pm 63.58 and $457.88 \pm 140.46$ ), neochlo- 
rogenic acid $(50.08 \pm 30.53$ and $87.90 \pm$ 19.42), caffeic acid (76.50 \pm 9.32 and $77.53 \pm 14.48)$ and vanillin $(11.52 \pm 1.38$ and $10.41 \pm 2.58$ ) respectively.

The contents in chlorogenic acid (CGA) and vanillin were on average higher at $3.97 \%$ and $9.63 \%$ respectively, on potatoes grown in EZ when compared to those from HA, while neochlorogenic and caffeic acids were lower in EZ in $43 \%$ and $1.34 \%$ than those from HA. The lower amount in EZ could be explained because neochlorogenic acid is an isomer of CGA, caffeic acid has probably been esterified by quinic acid to CGA, and both give the highest concentration for CGA in EZ.

The average values (mg/100 $\mathrm{g} \mathrm{DW})$ of CGA, caffeic acid and neochlorogenic were $467.34 ; 68.98$ and 77.00 respectively for both experimental sites, higher than those reported by André et al. (2009) for native potatoes grown in Huancayo and Huancani, Department of Junin (Peru) for the same metabolites $(441.2 ; 7.1 ; 5.8)$ and those reported by Narváez-Cuenca et al.,
(2012) for Victory potato purchased in supermarkets in Wageningen - The Netherlands $(25.43 ; 2.41 ; 1.16)$.

In this research the highest concentration of phenolic compounds was obtained for CGA (5-0 caffeoylquinic acid) and neochlorogenic acid (3-0 caffeoylquinic acid), and caffeic acid (trans-caffeic acid) giving a total of $613.32 \mathrm{mg} / 100 \mathrm{~g} \mathrm{DW}$.

This makes the native Huagalina potato a health-promoting agent as CGA acid and caffeic acid have been reported as inhibitors of carcinogenesis (Huang et al., 1998, Sancho and Pastore, 2012, Serafim et al., 2015), reducing obesity (Cho et al., 2010) hypotensive activity, providing cardiovascular protection (Susuki et al., 2002; Jiang et al., 2016).

Shi et al. (2016) showed that a new mechanism of CGA acid mediated in the protection of liver fibrosis (a stage before cirrhosis), inhibits oxidative stress and increases antioxidant defense and could become a promising new treatment for liver disease.

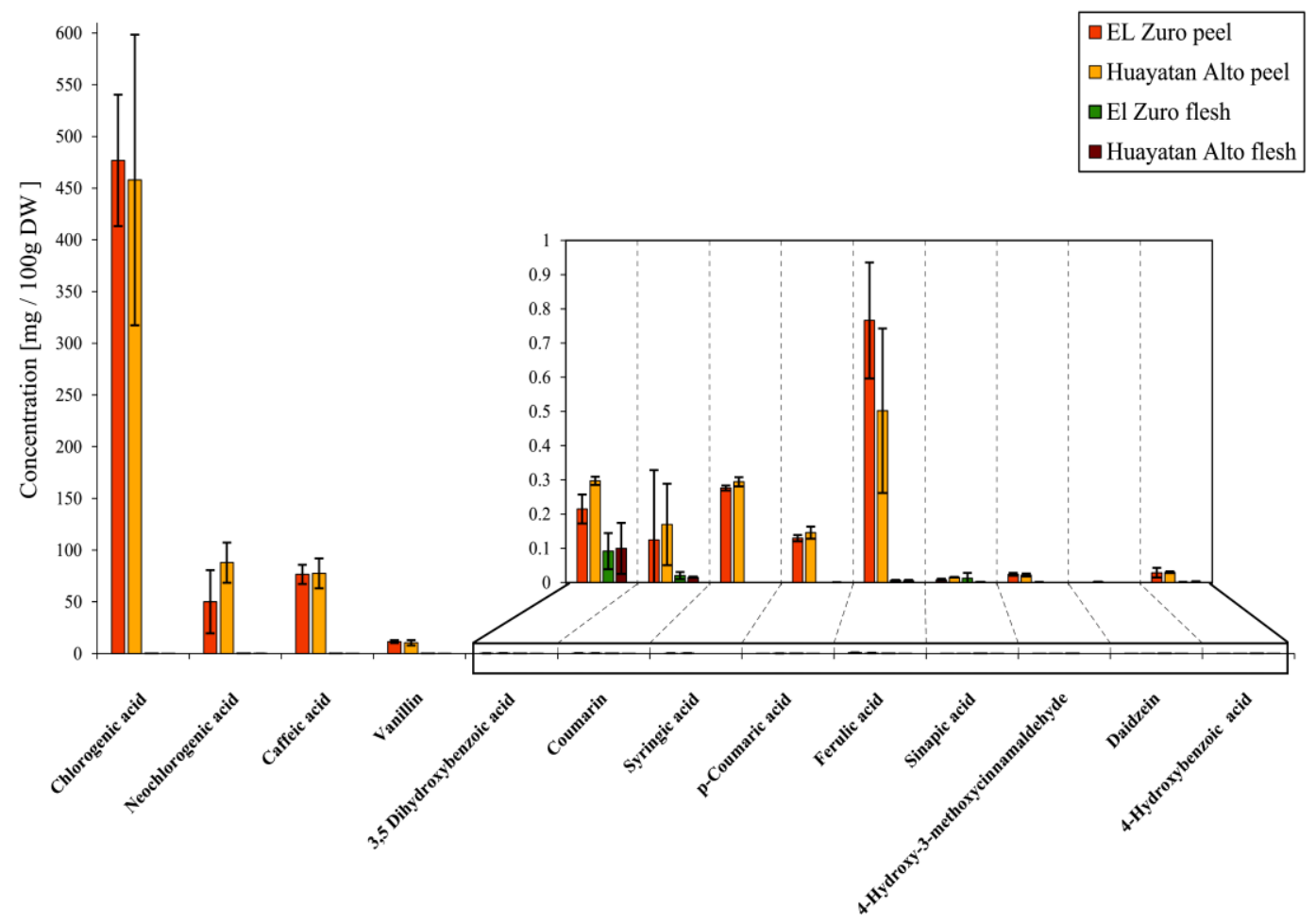

Figure 1. Phenolic compounds in peel and flesh in native Huagalina potato. 
Mikami and Yamazawa (2015) studied the protective effects of CGA acid on neuronal cell death induced by glutamate because the release of glutamate during cerebral ischemia triggers the death of neurons, suggesting that this polyphenol protects neurons from glutamate neurotoxicity by controlling calcium ion entry through glutamate receptors. Lirdprapamongkol et al., (2005) conducted in vitro studies and showed that vanillin has an inhibitory effect on invasion and migration of cancer cells; vanillin in vivo showed effects in reducing metastasis of lung tumor colonies compared with controls.

Phenolic compounds found in concentrations less than $1 \mathrm{mg} / 100 \mathrm{~g}$ DW (3,5-dihydroxybenzoic acid, coumarin, syringic acid, p-coumaric acid, ferulic acid, sinapic acid, 4-hydroxy-3-methoxy cinnamaldehyde and daidzein) are also important phytonutrients because potatoes are grown throughout the world and are consumed in large quantities and with fruits and vegetables complete the intake of antioxidants to prevent degenerative diseases (Lewis et al., 1999; Ezekiel et al., 2013). No genistein and 7-hydroxyflavone were detected, according to the literature both belong to the phenolic group of flavonoids (isoflavones); daidzein is mostly found in soy (Ludueña et al., 2007) and recent research has determined that it is also found in quinoa (Lutz et al., 2013). The PCA shows a visual description of different groups (Figure 2).

Component F1 shows a clear separation of the phenolic compounds. All of them are mostly located in the peel rather than in the flesh of potatoes grown in EZ and in HA, these results support those reported by other authors (Friedman, 1997; Lewis et al., 1999; Ji et al., 2012; Yang et al., 2016).

\section{Biplot (F1 and F2: $97.02 \%)$}

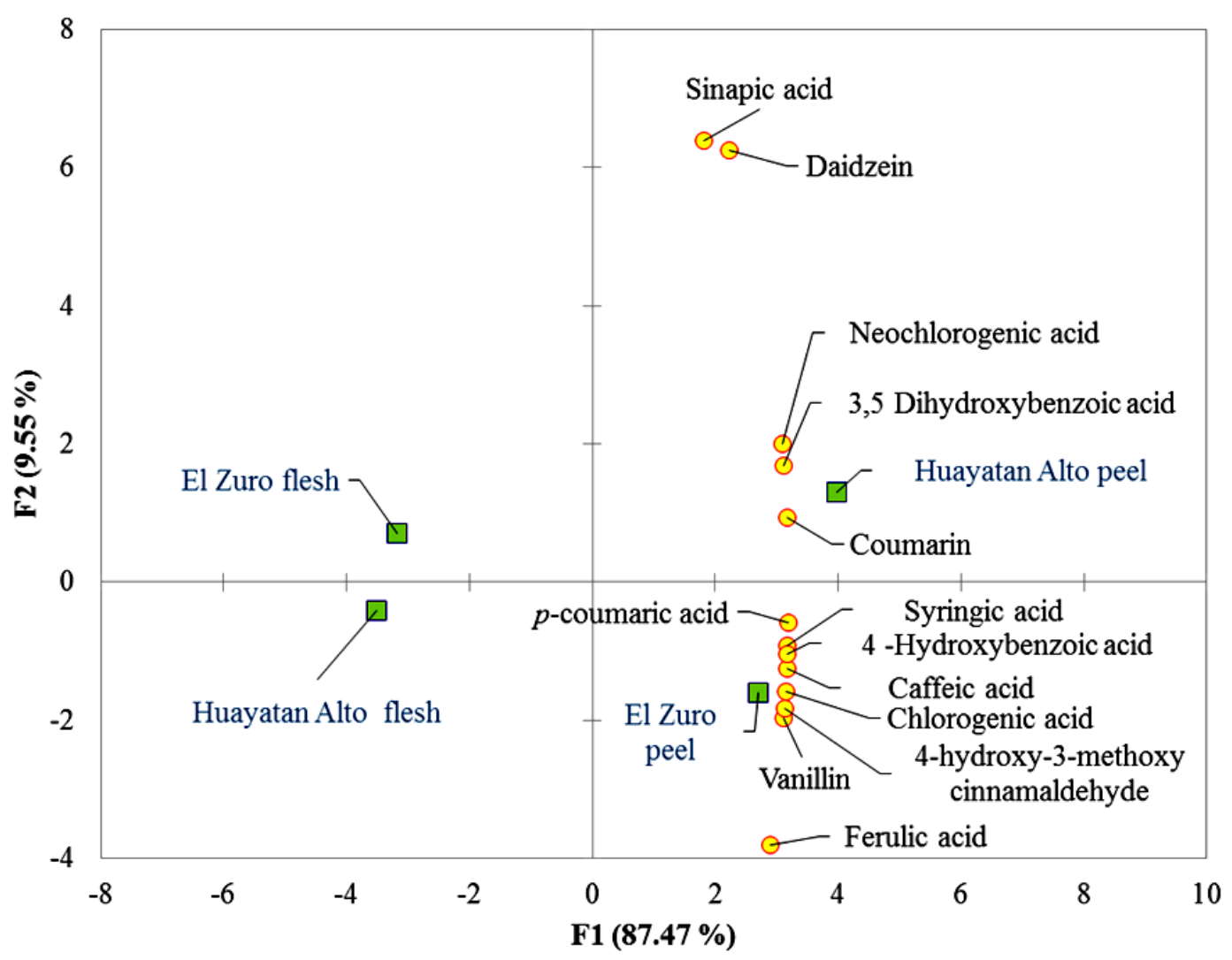

Figure 2. PCA of phenolic compounds in peel and flesh of native Huagalina potato. 
With respect to component $\mathrm{F} 2$, the peel of potatoes grown in EZ shows $62 \%$ of the metabolites studied; syringic acid, 4hydroxybenzoic and caffeic acid are strongly correlated and highly significant ( $r>0.90$ and $p<0.05)$, in the same way are chlorogenic acid, 4-hydroxy-3methoxycinnamaldehyde and vanillin.

The difference in phenolic content in crops in EZ and in HA could be explained by environmental differences in field trials, long culture days at low temperatures (Reyes et al., 2004), by the use of organic fertilizers and cold environment (Hajslova et al., 2005) and cultivation under drought stress (Delgado et al., 2001).

Information is still limited on the influence of organic and conventional farming on the content of phytonutrients; it has only been reported that organic farming has a high effect on potato tuber yield (Palmer et al., 2013) and the differences in protein content were not statistically significant (Bartova et al., 2013). Several researchers (André et al., 2009; Hamouz et al., 2010; Lachman et al., 2009; Reddivari et al., 2007; Wegener et al., 2009) highlight the prevalence of genotypic variation in environmental conditions.

André et al. (2009) examined the expression of thirteen genes involved in the biosynthetic pathway of polyphenols in five Andean potato genotypes using real time RT- PCR. They concluded that polyphenolic profiles are correlated to variations in gene expression profiles and further research is required to know the effect of environmental conditions. This correlation is a prerequisite to support breeding programs aiming to improve the functional value of this crop.

\section{Conclusions}

The native Huagalina potato contains phytochemicals that may help prevent degenerative diseases. UPLC-MS / MS detected thirteen phenolic compounds. Those in higher concentrations (mg/100 g DW) in El Zuro and Huayatan Alto respectively are: Chlorogenic acid (476.82 \pm 63.58 and $457.88 \pm 140.46)$, neochlorogenic acid $(50.08 \pm 30.53$ and $87.90 \pm 19.42)$, caffeic acid (76.50 \pm 9.32 and $77.53 \pm 14.48)$ and vanillin (11.52 \pm 1.38 and $10.41 \pm 2.58$ ). The PCA shows a clear separation of the phenolic compounds, all of them are in the peel. The metabolites found in lower concentration than $1 \mathrm{mg} / 100 \mathrm{~g}$ DW (acid 3,5-dihydroxybenzoic acid, coumarin, syringic acid, $p$ coumaric acid, ferulic acid, sinapic acid,4hydroxy-3-methoxycinnamaldehyde and daidzein) are also important sources of phytonutrients due to the high diet consumption of potatoes which becomes a good vehicle for antioxidant intake.

In conclusion, the native potato Huagalina have the genes that can be expressed in different biosynthetic pathways of the metabolites found in this research and this could be used for varietal recognition or "fingerprint" of this variety. Further research would be necessary to find out if cooking methods affect phytonutrients content.

\section{Acknowledgements}

Special thanks for Núcleo de Análise de Biomoléculas (NuBioMol) da UFV Viçosa (Brazil). We are also grateful to Financing Agency for financial support of related equipments (FINEP, CNPq, FAPEMIG).

\section{References}

André, Ch.; Schafleitner, R.; Guignard, C.; Oufir, M.; Alvarado, C.; Nomberto, G.; Hoofmann, L.; Hausman, J.; Evers, D.; Larondelle, Y. 2009. Modification of the health- promoting value of potato tubers field grown under stress: emphasis on dietary antioxidant and glycoalkaloid contents in 5 native Andean cultivars (Solanum tuberosum L.) J. Agric. Food Chem. 57: 599-609.

André, Ch.; Oufir, M.; Hoffmann, L.; Hausman, J.; Rogez, H.; Larondelle, Y.; Evers, D. 2009. Influence of environment and genotype on polyphenol compounds and in vitro antioxidant capacity of native Andean potatoes (Solanum tuberosum L.). Journal of Food Composition and Analysis 22: 517-524.

Bartova, V.; Divis, J.; Bartá, J.; Brabcova, A.; `Svajnerova, M. 2013. Variation of nitrogenous components in potato (Solanum tuberosum L.) tubers produced under organic and conventional crop management. Europ. J. Agronomy 49: 20- 31 .

Bordoloi, A.; Kaur, L.; Singh, J. 2012. Parenchyma cell microstructure and textural characteristics of raw and cooked potatoes. Food Chemistry 133(4): 1092-1100. 
Cho, A.; Jeon, S.; Kim, M.; Yeo, J.; Seo, K.; Choi, M. 2010. Chlorogenic acid exhibits anti-obesity property and improves lipid metabolism in high-fat diet-induced - obese mice. Food and Chemical Toxicology 48(3): 937-943.

Chuah, A.; Lee,Y.; Yamaguchi,T.; Takamura,H.; Yin, L.; Matoba, T. 2008. Effect of cooking on the antioxidant properties of coloured peppers. Food Chemistry 111(1): 20-28.

Delgado, E.; Sulaimann, M.; Pawelzik, E. 2001. Importance of chlorogenic acid on the oxidative potential of potato tubers of two German cultivars. Potato Research 44: 207-218.

Dixon, R.; Gang, D.; Charlton, A.; Fiehn, O.; Kuiper, H.; Reynolds, T.; Tjeerdema, R.; Jeffery, E.; German, B.; Ridley, W.; Seiber, J. 2006. Applications of Metabolomics in Agriculture. J. Agric. Food Chem 54: 8984-8994.

Ezequiel, R.; Singh, N.; Sharma, S.; Kaur, A. 2013. Beneficial phytochemicals in potato. A review. Food Research International 50: 487-496.

Friedman, M. 1997. Chemistry, Biochemistry and Dietary Role of potato polyphenols. A review: Journal of Agricultural and Food Chemistry 45: 1523-1540.

Hajslova, J.; Schulzova, V.; Slamina, P.; Janne, K.; Hellena, K.; Andersson, C. 2005. Quality of organically and conventionally grown potatoes: fouryear study of micronutrients, metals, secondary metabolites, enzymic browning and organoleptic properties. Food Aditives and Contaminants 22: 514534

Hamouz, K.; Lachman, J.; Hejtmankova, K.; Pazderu, K.; Cizek, M.; Dvorak, P. 2010. Effect of natural and growing conditions on the content of phenolics in potatoes with different fresh color. Plant Soil environment 56(8): 368-374.

Hawkes, J. 1990. The potato-evolution, biodiversity and genetic resources. Oxford: Belhaven Press.

Huang, M.; Smart, R.; Wong, C.; Cooney, A. 1988. Inhibitory effect of curcumin, chlorogenic acid, caffeic acid and ferulic acid on tumor promotion in mouse skin by 12-O- tetradecanoylphorbol-13-acetate. Cancer Research 48(21): 5941-5946.

Ignat, I.; Volf, I.; Popa, V. 2011. A critical review of methods for characterization of polyphenolic compounds in fruits and vegetables. Food Chemistry 126: $1821-1835$.

INEI. 2014. Instituto Nacional de Estadística e Informática. Presidencia del Consejo de Ministros. Perú. Disponible en:

https://www.inei.gob.pe/prensa/noticias/produccionde-papa-crecio-45-7582/

Jiang, R.; Hodgson, J.; Mas, E.; Croft, K.; Ward, N. 2016. Chlorogenic acid improves ex vivo vessel function and protects endothelial cells against HOCL-induced oxidative damage, via increased production of nitric oxide and induction of Hmox-1. Journal of Nutritional Biochemistry 27: 53-60.

Ji, X.; Rivers, L.; Zelinski, Z.; Xu, M.; Mac Dougal, E.; Stephen, J.; Zhang, S.; Wang, Y.; Chapman, R.; Keddy, P.; Robertson, G.; Kirby, C.; Embleton, J.; Worrall, K.; Murphy, A.; De Koeyer, D.; Tai, H.; Yu, L.; Charter, E.; Zhang, J. 2012. Quantitative analysis of phenolic components and glycoalkaloids from 20 potato clones an in vitro evaluation of antioxidant, cholesterol uptake and neuroprotective activities. Food Chemistry 133: 1177-1187.

Kris-Etherton, P.; Lefevre, M.; Beecher, G.; Gross, M.; Kenn, C.; Etherto, T. 2004. Bioactive compounds in nutrition and health-research methodologies for establishing biological function: the antioxidant and anti-inflammatory effects of flavonoids on atherosclerosis. Annual review of nutrition 24: 511538.

Lachman J.; Hamouz, K.; Sulc, M.; Orsack, M.; Pivec, V.; Hejtmankova, A. 2009. Cultivar differences of total anthocyanins and anthocyanidins in red and purplefleshed potatoes and their relation to antioxidant activity. Food Chemistry 114(3): 836-843.

Lewis, C.; Walker, J.; Lancaster, J. 1999. Changes in anthocyanin, flavonoid and phenoic acid concentrations during development and storage of coloured potato (Solanum tuberosum L.) tubers. Journal of the Science of Food Agriculture 79: 311316

Lirdprapamongkol, K.; Sakurai, H.; Kawasaki, N.; Choo, M.; Saitoh, Y.; Aozuka, Y.; Singhirunnusorn, P.; Ruchirawat, S.; Svasti, J.; Saiki, I. 2005. Vanillin suppresses in vitro invasion and in vivo metastasis of mouse breast cancer cells. European Journal of Pharmaceutical Sciences 25: 57-65.

Ludueña, B.; Mastandrea, C.; Chichizola, C.; Franconi, M. 2007. Isoflavonas en soja, contenido de daidzeína y genisteína y su importancia biológica. Bioquímica y Patología Clínica 71(1): 54-66.

Lutz, M.; Martínez, A.; Enrique A.; Martínez, B. 2013. Daidzein and Genistein contents in seeds of quinoa (Chenopodium quinoa Willd.) from local ecotypes grown in arid Chile. Centro de Investigación y Desarrollo de Alimentos Funcionales CIDAF, Facultad de Farmacia, Universidad de Valpa Industrial Crops and Products 49: 117- 121.

Mikami, Y.; Yamazawa, T. 2015. Chlorogenic acid in coffee protects neurons against glutamate neurotoxicity. Life Sciences 139: 69-74.

Monro, J.; Mishra, S. 2009. Nutritional Value of Potatoes: Digestibility, Glycemc Index and Glycemic Impact. Advances in Potato Chemistry and Technology (First Edit.). 371-394. Elsevier. Ltd.

Muthswamy, S.; Rupasinghe, H. 2007. Fruit phenolics as natural antimicrobial agents: Selective antimicrobial activity of catechin, chlorogenic acid and phloridzin. Journal of Food, Agric. and Envir. 5: 81-85.

Narváez-Cuenca, C.; Vincken, J.; Gruppen, H. 2012. Identification and quantification of (dihydro) hidroxycinnamic acids and their conjugates in potato by UHPLC-DAD-ESI-MS. Food Chemistry 130: 730738.

Navarre, A. 2009. Nutrional Value of Potatoes: Vitamin, phytonutrient and Mineral Content. Advances in Potato Chemistry and Technology (First Edit).

Palmer, M.; Cooper, J.; Tetard-Jones, C.; Srednicka-Tober, D.; Baranski, M.; Eyrea, M.; Shottona, P.; Volakakis, N.; Cakmak, I. Ozturk, L.; Leifert, C; Wilcockson, S.; Bilsborrow, P. 2013. The influence of organic and conventional fertilization and crop protection practices, preceding crop, harvest year and weather conditions on yield and quality of potato (Solanum tuberosum L.) in a long- term management trial. Europ. J. Agronomy 49: 83-92.

Reddivari, L.; Hale, A.; Miller, J. 2007. Genotype, location and year influence antioxidant activity, carotenoid content, phenolic content and composition in specially potatoes. Journal of Agricultural and Food Chemistry 55(20): 8073-8079.

Reyes, L.; Miller, J.; Cisneros-Zevallos, L. 2004. Enviromental conditions influence the content and yield of anthocyanins and total phenolics in purple and red flesh potatoes during tuber development. American Journal of Potato Research 81: 187-193. 
Sancho, R.; Pastore, G. 2012. Evaluation of the effects of antiocyaninsin type 2 diabetes. Food Research International 46(1): 378-386.

Sandoval-Vegas, M.; Huamán-Gutiérrez, O.; OréSifuentes, R.; Loli-Ponce, A.; Ayala-Pio, S. 2010. An Fac med. 71(3): 47-152.

Sandoval, M.; Tenorio, J.; Tinco, A.; Loli, R,; Calderón S. 2015. Efecto antioxidante y citoprotector del tocosh de Solanum tuberosum en la mucosa gástrica de animales de experimentación. An Fac med. 76(1): 15-20.

Serafim, T.; Milhazes, N.; Borges, F.; Oliveira, P. 2015. Chapter 74 - Caffeic and Ferulic Acid Derivatives: Use in Breast Cancer. Coffee in Health and Disease Prevention. Edited by Victor Preedy.

Sharma, O.; Bhat, T. 2009. DPPH antioxidant assay revisited. Food Chemistry 113: 1202-1205.

Shi, H.; Shi, A.; Ding, L.; Lu, X.; Wang, Y.; Zhao, J.; Dai, F.; Guo, X. 2016. Chlorogenic acid protects against liver fibrosis in vivo and in vitro through inhibiton of oxidative stress. Clinical Nutrition (In press).

Susuki, A.; Kagawa, D.; Ochial, R.; Tokimitsu, I.; Saito, I. 2002. Green coffee bean extract and its metabolites have hypotensive effect in spontaneously hypertensive rats. Hypertension Research 25(1): 99-107.
Tamura, H.; Akioka, T.; Ueno, K.; Chujyo, T.; Osaki, K.; King, P. 2006. Anti-human immunodeficiency virus activity of 3,4,5 -tricaffeoylquinic acid in cultured cells of lettuce leaves. Molecular Nutrition and Food Research 50: 396-400.

Virgili, F.; Scaccini, C. 2003. Nutritional phenolics and cardiovascular diseases. In: Johnson, I., G. Williamson, E (Eds.). Phytochemical Functional Foods. Wood-head, Cambridge, UK, 5-17.

Wegener, C.; Jansen, G.; Juergens, H.; Schuetze, W. 2009. Special quality traits of coloured potato breeding clones: Anthocyanins, soluble phenols and antioxidant capacity. Journal of the Science of Food and Agriculture 89(2): 206-215.

Yang, Y.; Achaerandio, M; Pujolá, M. 2016. Effect of intensity of cooking methods on the nutritional and physical properties of potato tubers. Food Chemistry 197: 1301-1310.

Zhao, Z.; Moghadasian, M. 2010. Bioavailability of hydroxycinnamates: A brief review of in vivo and in vitro studies. Phytochemistry Reviews 9: 133-145. 